\title{
Long delay learning in the T-maze: Effect of reward given in the home cage
}

\author{
BOW TONG LETT \\ Memorial University of Newfoundland, St. John's, Newfoundland, Canada
}

\begin{abstract}
Learning of a spatial discrimination in a T-maze with long delayed reward has been demonstrated by means of a procedure in which the rat is removed after a response to spend the delay in its home cage and later is returned to the T-maze for reward. This procedure was derived from Revusky's (1971, in press) concurrent interference theory of long delay learning. According to this theory, the usual decrement in learning with a delay of reward is the result of concurrent interference produced when the response and/or reward become involved in extraneous associations with delay events. Removal of the rat to spend the delay outside of the T-maze minimizes concurrent interferences by reducing the associability of the delay events with respect to the events that occur inside the T-maze such as the response and the reward. The present experiments were concerned with a corollary of this theory: If events occurring in the home cage are not readily associated with events occurring in the T-maze, then a reward should be less effective when administered in the home cage than when administered in the T-maze. It was found that learning is retarded when reward is given in the home cage; however, reward given in the home cage as much as $2 \mathrm{~min}$ after a response produces learning.
\end{abstract}

Lett $(1973,1975)$ showed that rats can learn a spatial discrimination in a T-maze with delays of reward lasting as long as $1 \mathrm{~h}$. The unusual feature of the procedure was that the response and the reward occurred in one place, the T-maze, while the events of the delay were made to occur in another place, the home cage. After the rat entered a choice chamber, whether correct or incorrect, it was removed and placed in its home cage to spend the delay interval. When the delay ended, the animal was returned to the startbox of the T-maze which contained a reward following a correct choice or was empty following an incorrect choice.

This procedure was based on Revusky's (1971, in press) analysis of long delay learning as a problem of selective association. According to Revusky, the main reason a reference event $A$ does not become associated with the delayed reference event $B$ is that $A$ and $B$ are usually as likely to become associated with extraneous delay events as with each other. To the extent that A and $B$ become associated with extraneous events, these extraneous associations will interfere with, or reduce the probability of, the reference association between A and delayed B. If so, the occurrence of long delay learning implies the operation of a principle of selective association by which $\mathrm{A}$ and $\mathrm{B}$ are strongly associable with respect to each other and only weakly associable with respect to the events of the delay.

This research was supported by National Research Council of Canada Grant A8270. I am grateful to S. Revusky for reading this paper and to A. Dawe for technical assistance. Reprint requests should be sent to Bow Tong Lett, Department of Psychology, Memorial University of Newfoundland, St. John's, Newfoundland, Canada.
In the case of flavor aversion learning, the principle of selective association that permits long delay learning has been called stimulus relevance (Capretta, 1961; Revusky, 1971, in press; Revusky \& Garcia, 1970). By the principle of stimulus relevance, flavor and sickness, the reference events to be associated over a delay, can be classified as internal events because they have an important role in the regulation of the animal's internal milieu; in contrast, the events that normally occur during the delay, such as the animal's own movements and the sights and sounds of the environment, can be classified as external events because they are important for the regulation of the animal's external milieu. Garcia (Garcia \& Koelling, 1966; Garcia, McGowan, \& Green, 1972) has shown that flavor and sickness are strongly associable with respect to each other and very weakly associable with respect to external events.

In the case of Lett's demonstration of learning with long delayed reward in the T-maze, the principle of selective association might be called situational relevance (Revusky, 1971, in press). The principle of situational relevance was closely modeled after stimulus relevance. Unlike stimulus relevance, however, the selective association described by situational relevance does not depend upon a difference in type or class of events such as an internal-external dichotomy. Revusky postulated that a difference in place of occurrence, rather than of class of event, could be a basis for selective association. For example, in Lett's experiment, the response and delayed reward are highly associable to each other because they both occur in the same situation and are only weakly associable to the delay events which occur in a different situation, the home cage. As a result, the delay events should produce little interference with the association 
between the response and delayed reward. Since learning with such long delayed reward was not predicted on an a priori basis by any other theory, Lett's findings provide strong but indirect evidence for the existence of situational relevance. The present experiments were attempts to obtain more direct evidence.

\section{EXPERIMENT 1}

The principle of situational relevance is that two events are more readily associated when both events occur in the same situation than when each occurs in a different situation. As applied to Lett's demonstration of long delay learning in the T-maze, the concept of situational relevance can be translated into the following experimental prediction: The procedure of rewarding the animal outside of the training situation will at least impair, if not entirely prevent, learning with delayed reward.

Some confirmation of this prediction can be found in Denny's (1974) experiment. In this experiment, two groups of rats were trained to perform a spatial discrimination in a T-maze with a procedure similar to that used by Lett (1973). Briefly, Denny's procedure was as follows. After the rat entered a choice chamber, it was removed and placed in its home cage to spend the delay. When the delay interval ended, the rat was given reward following a correct response. The rats in one group received reward in a wastebasket, while the rats in a second group were rewarded in the startbox of the T-maze. After an incorrect response, however, the rat regardless of group was always returned to the startbox and allowed to make another choice response. Each day this procedure was administered until the rat made a single correct choice and obtained reward. A delay interval of 1.5-2.0 min, spent in the home cage, followed each choice response, whether correct or incorrect. Denny found that learning was slower when the rat was rewarded in the wastebasket than when it was rewarded in the startbox.

Denny's (1974) results are favorable to the hypothesis of situational relevance in that a reward outside of the apparatus produced slower learning than reward given inside the apparatus. The fact that rats rewarded in the wastebasket were able to learn at all might be attributed to two factors. The first is that the rats rewarded in the wastebasket did not actually associate between the correct response and reward; rather the discrimination performance of these animals could have been mediated in part by an association between the incorrect response and failure to obtain reward. Under Denny's training procedure, a rat was always returned to the startbox after an incorrect response; thus, feedback for an incorrect response was given in the startbox of the T-maze. The second possibility is that the rat generalized between the T-maze and the wastebasket because both were novel, confined situations of relatively short duration and because the handling stimuli, produced by the experimenter in the course of administering the experimental procedure, were closely related to both of these situations.
To eliminate, insofar as feasible, any extraneous basis for situational relevance, the present experiment used a procedure that differs from Denny's procedure in two important respects: (1) Each rat was given a single choice trial each day to exclude any possibility of feedback for an incorrect response in the T-maze. (2) The animals were rewarded in the home cage instead of a separate chamber outside of the T-maze. The procedure of rewarding the animals in the home cage has two advantages. (1) The home cage is highly familiar to the animal and, thus, should be maximally discriminable from the T-maze. (2) The reward can be inserted into the home cage without further handling of the animal by the experimenter; this should further reduce the similarity between training and reward situations.

\section{Method}

Subjects. Thirty male adult albino rats were gradually reduced to $80 \%$ of their free-feeding weights. They were housed in a standard rack of stainless steel cages. Water was continuously available.

Apparatus. The training apparatus was a truncated T-maze (Lett, 1973, 1975) consisting of a startbox $(30.5 \times 17.8 \times$ $15.2 \mathrm{~cm})$ flanked on either side by an endbox $(33.0 \times 12.7 \times$ $15.2 \mathrm{~cm})$. The startbox had gray walls, the left endbox had white walls and the right endbox, black walls. One-way doors made of clear plastic separated the choice chambers from the startbox and prevented retracing; these doors could be locked so as to confine the rat to the startbox.

Procedure. Prior to the start of training, the rats were given two kinds of preliminary treatments. One treatment consisted of placing the rats on several occasions in groups of 10-15 in a small open field, which they were allowed to explore. The object of this treatment was to reduce the emotionality of the rats to novel situations. The second pretraining treatment consisted of giving the rats two exposures to the reward substance, $2.5 \mathrm{ml}$ of $25 \% \mathrm{w} / \mathrm{v}$ sucrose solution administered in a small glass dish. For this treatment, the rats were divided into two groups. One group of rats received the reward substance in the startbox and continued to do so throughout the remainder of the experiment; these rats were placed in the locked startbox with the small dish containing sucrose solution. For a second group, destined to receive reward in the home cage, the dish of sucrose solution was introduced into the home cage manually by the experimenter.

The two groups of rats were then trained to perform a spatial discrimination in the truncated T-maze. For 8 of the 15 rats in each group, the left-white choice chamber was designated as the correct choice; for the remainder, the right-black chamber was correct. Each day's training consisted of a single choice trial. At the beginning of the trial, the rat was placed into the startbox. Immediately after the rat entered an endbox, it was removed and placed in its home cage to spend a delay of $1 \mathrm{~min}$. When the delay interval ended, feedback was given for a correct response. If the rat was to be rewarded in the startbox, it was picked up by the experimenter and placed in the startbox, where it found a small dish containing $2.5 \mathrm{ml}$ of sucrose solution. If it was to be rewarded in the home cage, the experimenter inserted the small dish of sugar water into the home cage. In neither group was feedback given for an incorrect response; the animal was simply left undisturbed in its home cage until its usual feeding time $30-40 \mathrm{~min}$ after the training trial, at which time several chow pellets were placed in the feeder that hung outside of each rat's cage. The rats were trained for 90 days.

\section{Results and Discussion}

The analysis of variance indicated that the interpretation of these results must take into account the 
marked unlearned preference of the rats for the right endbox. Thus, separate learning curves for each of the four groups, formed by combining a place of reward with a side of rewarded response, are presented in Figure 1. These groups are the following: Groups SBL and SBR, which received reward in the startbox for a left and a right choice, respectively; Groups HCL and HCR, which received reward in the home cage for a left and a right choice, respectively.

As can be seen from Figure 1, the rats rewarded in the startbox for a right-black choice response (Group SBR) chose the correct side more often overall than did the rats in SBL. However, the pattern of performance over blocks was similar in the two groups. Both Groups SBR and SBL learned the discrimination as evidenced by the presence of a significant linear trend over blocks in each group $[F(1,48)=61.99, p<.001$, for Group SBR; $\mathrm{F}(1,56)=7.22, \mathrm{p}<.01$, for Group SBL] .

A similar, more marked, difference in overall performance was obtained between Groups HCL and HCR. Unlike the groups rewarded in the startbox, Group HCL exhibited a different pattern of performance over blocks than Group HCR. By the criterion of a significant linear trend over blocks, the rats in Group HCR learned $[\mathrm{F}(1,48)=10.29, \mathrm{p}<.01]$, while the rats in Group HCL did not $(p>.10)$. From such results, it is clearly inappropriate to conclude that a rat is unable to associate between a choice response made in the T-maze and delayed reward given in the home cage.

\section{EXPERIMENT 2}

The results of Experiment 1 suggested that rats were able to associate between a choice response made in the T-maze and delayed reward delivered in the home cage when the discrimination problem was relatively easy

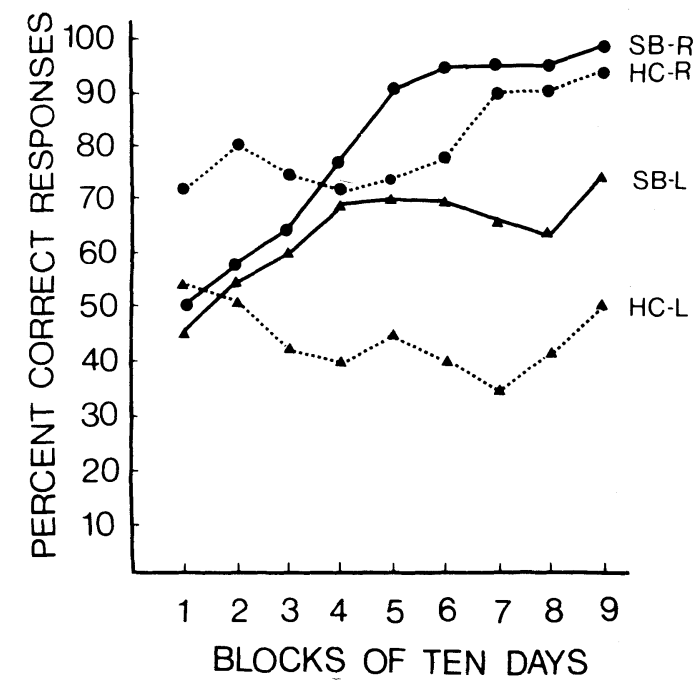

Figure 1. Percentage of correct responses in blocks of 10 days for rats rewarded in the startbox after a right choice response (SB-R) or a left choice (SB-L) and for rats rewarded in the home cage after a right (HC-R) or a left (HC-L) choice response. (i.e., when the rewarded choice was also the strongly preferred side of the T-maze). Since no learning at all was detected when the less preferred side of the T-Maze was rewarded, the animal's ability to learn with delayed reward delivered outside of the training apparatus appears to be marginal. If so, learning might be entirely eliminated by a slight increase in length of delay. With this expectation, a second experiment varied the length of the delay between the choice response and the delivery of reward in the home cage. Different groups of rats received reward after delays of $0,15,60$, or $120 \mathrm{sec}$.

\section{Method}

Subjects. Forty male adult albino rats were gradually reduced to $80 \%$ of their free-feeding weights. Prior to the start of training, these rats, like those in Experiment 1, were allowed to explore in an open field and given two exposures to the reward substance in the home cage.

Procedure. The procedure was almost identical to that described above for Groups HCL and HCR in Experiment 1. Briefly, the rats were divided into four groups and given a single choice trial each day in the truncated T-maze. Half of each group of 10 rats was rewarded for a left-white choice and the remainder for a right-black choice. Reward for a correct response was always given in the home cage after the appropriate delay. Group HC-O received reward in the home cage immediately after removal from the T-maze; Groups HC-15, HC-60, and HC-120 received reward after a delay of 15,60 , or $120 \mathrm{sec}$, respectively, spent in the home cage. No feedback was given for an incorrect choice response; the rat was simply left undisturbed until its usual feeding time, $30-40 \mathrm{~min}$ after the training trial was completed. The rats were trained for 100 days.

\section{Results and Discussion}

The analysis of variance indicated that left-right preferences were not a significant factor in this experiment. Thus, Figure 2 shows the percentage of correct responses during each block of 10 days for each group without regard for side of rewarded choice. As Figure 2 suggests, the rats in Group HC-0 made more correct responses overall than those in Group HC-60 $[\mathrm{F}(1,31)=$ $78.78, \mathrm{p}<.001]$ or in Group HC-1 $20[\mathrm{~F}(1,31)=68.10$, $\mathrm{p}<.001$ ]; similarly, the rats in Group HC-15 made more correct responses overall than those in Group HC-60 $[F(1,31)=47.70, \quad p<.001]$ or in Group HC-120 $[F(1,31)=40.08, p<.001]$. There was no statistically reliable difference in overall performance between Groups HC-0 and HC-15 $(.10>p>.05)$ or between Groups HC-60 and HC-120 (F < 1.0). However, the expectation of no learning with an increase in length of delay to $120 \mathrm{sec}$ was quite incorrect; each group improved in performance over blocks by the criterion of a significant linear trend $[F(1,81)=77.68, p<.001$, for Group HC-0; $\mathrm{F}(1,81)=43.27, \mathrm{p}<.001$, for Group HC-15; $\mathrm{F}(1,81)=$ $16.02, \mathrm{p}<.001$, for Group HC-60; $F(1,72)=9.28$, $\mathrm{p}<.01$, for Group HC-120]. In short, the results of these experiments are in close agreement with those obtained by Denny (1974). They indicate that delayed reward given in a place that should be discriminably different from the training apparatus impairs, but does not prevent, learning. 


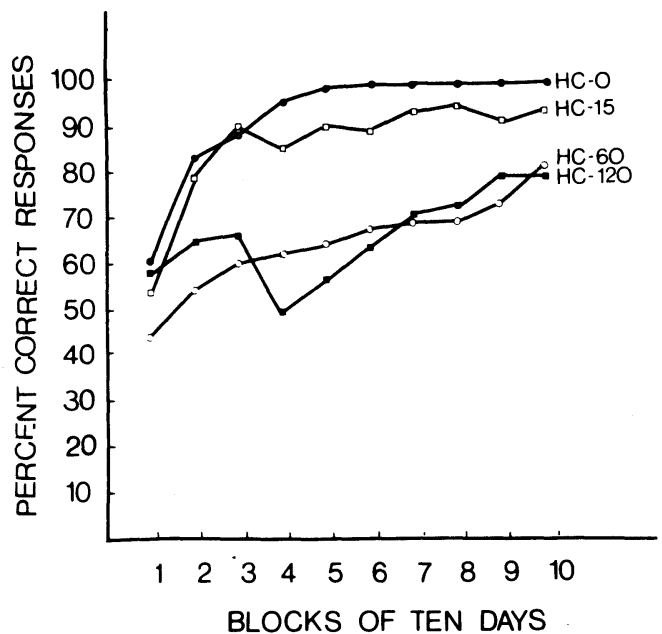

Figure 2. Percentage of correct responses in blocks of 10 days for groups rewarded in the home cage after a delay of 0,15 , 60 , or 120 sec.

\section{GENERAL DISCUSSION}

Revusky's (1971, in press) concurrent interference theory clearly predicts that learning will be hindered when delayed reward is given outside of the training apparatus. In this respect, the results of Experiment 1 are supportive of Revusky's theory. In another respect, these same results and those of Experiment 2 can be considered extremely embarrassing to Revusky's theory because the theory can be interpreted as implying that no learning at all ought to occur when delayed reward is given in the home cage. When the rat makes the correct choice response in the T-maze, is then delayed and rewarded in the home cage, the events occurring in the home cage prior to the reward ought to be more associable with reward than is the response. If so, extraneous associations between delay events and reward should occur and strongly interfere with the response-reward association.

However, the present findings can be explained in terms of the situational relevance hypothesis. Conceivably, the presence and actions of the experimenter might have provided a basis for situational relevance between the response and reward. After all, the experimenter was an important common element of both the training and reward situations and much less a part of the delay situation. The experimenter took the rat to the T-maze, hovered above the rat until it made a choice response, and then removed the rat after the response; later, if appropriate, he placed the reward in the home cage. In contrast, the rat is left undisturbed during the delay as it is during most of the day. Thus, the common contextual stimuli provided by the experimenter might have increased the associability of the training events with respect to the delayed reward and facilitated learning.

It should be noted that Denny's (1974) results and those of the present experiment provide equal support for an alternative explanation of intertrial discrimination learning and Lett's findings of long delay learning in the T-maze. This view (Capaldi, 1971; Lett, in press; Roberts, 1976) assumes that reactivation or retrieval of memory plays an important role in intertrial discriminations and learning with long delayed reward in the T-maze. According to this view, returning the animal to the training situation reactivates memory of the events that previously occurred there. For example, consider Lett's T-maze experiment. Memory of the choice response is reactivated when the animal is returned to the startbox after the delay. When the memory of the choice response is active at the time of reward, the choice response is assumed to become associated with the reward. Like the situational relevance hypothesis, this view also tends to predict that no learning will occur when delayed reward is given outside of the training situation. The reason is that when reward is given outside of the training situation, there should be no events to reactivate memory of the choice response. However, the same kind of argument advanced in defense of the situational relevance hypothesis can also be made here as follows. The stimuli produced by the experimenter may be perceived by the rat as attributes of the training situation. If so, stimuli produced by the experimenter in the delivery of reward might serve to reactivate memory for training events so that memory of the choice response is active at the time of reward. Unfortunately, the present results do not distinguish between reactivation of memory and situational relevance as possible mechanisms underlying long delay learning in runways and T-mazes.

\section{REFERENCES}

Capaldi, E. J. Memory and learning: A sequential viewpoint. In W. K. Honig \& P. H. R. James (Eds.), Animal memory. New York: Academic Press, 1971. Pp. 111-154.

Capretta, P. J. An experimental modification of food preferences in chickens. Journal of Comparative and Physiological Psychology, 1961, 54, 238-242.

DENNY, M. R. Recent explorations in a T-maze: Women's lib, long delays and all that. Presidential address, Midwestern Psychological Association Meeting, Chicago, 1974.

Garcia, J., \& Koelling, R. A. Relation of cue to consequence in avoidance learning. Psychonomic Science, $1966,4,123-124$.

Garcia, J., McGowan, B. K., \& Green, K. F. Biological constraints on conditioning. In M. E. P. Seligman \& J. L. Hager (Eds.), Biological boundaries of learning. New York: Appleton-Century-Crofts, 1972. Pp. 21-43.

LETT, B. T. Delayed reward learning: Disproof of the traditional theory. Learning and Motivation, 1973, 4, 237-246.

LETT, B. T. Long delay learning in the T-maze. Learning and Motivation, 1975, 6, 80-90.

LETT, B. T. Long delay learning: Implications for learning and memory theory. In N. S. Sutherland (Ed.), Tutorial essays in psychology. Hillsdale. N.J: Erlbaum, in press.

ReVusky, S. The role of interference in association over a delay. In W. K. Honig \& P. H. R. James (Eds.), Animal memory. New York: Academic Press, 1971. Pp. 155-213.

REVusky, S. The concurrent interference approach to delay learning. In L. M. Barker, M. R. Best, \& M. Domjan (Eds.), Learning mechanisms in food selection. Waco, Tex: Baylor University Press, in press.

REVUSKY, S., \& GARCIA, J. Learned associations over long delays. In G. H. Bower \& J. T. Spence (Eds.), The psychology of learning and motivation: Advances in research and theory (Vol. 4). New York: Academic Press, 1970. Pp. 1-84.

RoberTs, W. A. Failure to replicate visual discrimination learning with a 1-min delay of reward. Learning and Motivation, 1976, 7, 313-325.

WINER, B. J. Statistical principles in experimental design. New York: McGraw-Hill, 1962.

(Received for publication May 23, 1977.) 